\title{
In Memoriam: Dr. Shibendu Shankar Ray (July 02, 1963 - May 04, 2021)
}

\author{
SP Aggarwal ${ }^{1}$
}

(C) Indian Society of Remote Sensing 2021

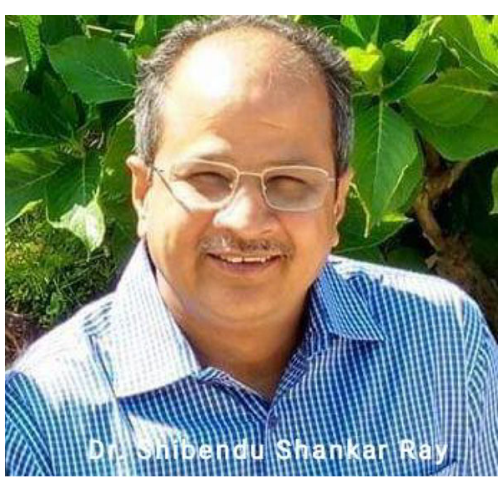

Dr. Shibendu Shankar Ray

July 02, 1963 - May 04, 2021

A person aptly called a leader who leads by example, Dr. Shibendu Shankar Ray belongs to that genre of people who can radiate energy and bring a smile on your face, even in an adversity. In addition to being a vivacious person, he was always helpful and took a lead role in the organization of things, be it official or inter-personal. He was a ray of enthusiasm, energy, positivity and happiness.

As a remote sensing scientist, he had many feathers donned in his cap, notably amongst them are the monitoring of agriculture, suggesting post harvest storage locations, cropping systems analysis, precision farming studies etc. His stint as the founder Director of MNCFC, MoA \& FW, New Delhi, has brought laurels both to the remote sensing society as well as to the department. His contribution to the Indian Society of Remote Sensing had been exemplary. He had conducted many workshops and conferences. He was the Chair of the Working Group: WG VIII/6 of the ISPRS: Agriculture, Ecosystem and Biodiversity, Joint Secretary and Second Vice President of the ISRS in various terms. Currently, he was the Associate Editor of the Journal of the Society. For his scientific endeavour and zeal for the society's activities, he has been awarded the PR Pisharoty Award in the year 2006 and the Satish Dhawan award in the year 2014, in addition to other ISRO awards.

The Society mourns the untimely passing away and pays its tributes to one of its bright and energetic members. May the soul attain eternal peace.

Publisher's Note Springer Nature remains neutral with regard to jurisdictional claims in published maps and institutional affiliations.

SP Aggarwal

spa.jisrs@gmail.com

1 Indian Institute of Remote Sensing, Dehradun, India 